Revista lus et Praxis, Año 18, № 1, 2012, pp. 37 - 60

ISSN 0717 - 2877

Universidad de Talca - Facultad de Ciencias Jurídicas y Sociales

"Régimen especial de reconocimiento de la personalidad jurídica de derecho público en la ley

№ 19.638. Marco legal aplicable a las iglesias Católica y Ortodoxa"

Jorge Del Picó Rubio

\title{
RÉGIMEN ESPECIAL DE RECONOCIMIENTO DE LA PERSONALIDAD JURÍDICA DE DERECHO PÚBLICO EN LA LEY No 19.638. MARCO LEGAL APLICABLE A LAS IGLESIAS CATÓLICA Y ORTODOXA*
}

\author{
THE 19,638 ACT SPECIAL REGIME FOR THE RECOGNITION
}

OF PUBLIC LAW PERSONALITY.

LEGAL REGULATION APPLICABLE TO CHATOLIC AND ORTHODOX CHRUCHES

Jorge Del Picó Rubio**

\begin{abstract}
RESUMEN
La Ley No 19.638, sobre Constitución Jurídica de las Iglesias y Organizaciones Religiosas, reguló civilmente a las organizaciones religiosa chilenas, sobre la base de una distinción fundamental entre aquellas entidades preexistentes en el goce de la personalidad jurídica de derecho público y las que, a partir de la fecha de entrada en vigor de la ley, manifestaran su pretensión de adquirirla. Dicha diferencia, contempló

el establecimiento de un régimen general, aplicable a todas las organizaciones y grupos religiosos que no gozaren de dicha personalidad de derecho público al momento de la entrada en vigor de la ley, y un régimen especial, consistente en el reconocimiento de la preexistencia de esta calidad jurídica, en favor de aquellas entidades que, al momento de la entrada en vigencia de la ley, ya gozaban de ella, vale decir, la Iglesia Católica, apostólica y romana y a la Iglesia Ortodoxa, tributaria del Patriarcado de Antioquia. El propósito del trabajo tiene por objetivo exponer este régimen jurídico especial, precisando el marco normativo aplicable, fijando sus fuentes directas y el contexto material de su producción, determinando sus efectos y anticipando una solución coherente a las cuestiones interpretativas emergentes.

En particular, analiza el estatuto de la Iglesia católica desde la perspectiva del

Derecho eclesiástico del Estado de Chile, proponiendo una lectura actual de su situación jurídica, que intenta resolver una de las cuestiones más debatidas durante la tramitación de este cuerpo normativo y cuyos efectos aún perduran en el presente.
\end{abstract}

\section{ABSTRACT}

The 19,638 Act, which deals with the incorporation of churches and religious organizations, regulated the Chilean religious organizations from a civil law perspective by distinguishing those organizations that already had a public law personality and

\footnotetext{
*Trabajo recibido 21 de marzo y aprobado el 20 de abril de 2012.

${ }^{*}$ Doctor en Derecho de la Universidad de Zaragoza, España; Profesor de Derecho Civil y Ciencias del Derecho en la Facultad de Ciencias Jurídicas y Sociales de la Universidad de Talca. Correo electrónico: jlp@utalca.cl.
} 
those that could acquire this personality from there on. This distinction supposed establishing, on the one hand, a general regime for churches and religious groups lacking this personality by the time the law went into effect and, on the other hand,

a special regime for churches that already had this personality that consisted of recognizing this preexisting legal personality, namely, the Roman, Catholic Apostolic Church and the Orthodox Church linked to the Antioch Patriarchy. This article deals with this special regime by shedding light on the legal framework, the direct sources and material context that presided over the regime creation process, and the effects of this regime. It also anticipates a coherent solution for the emerging interpretative issues. Particularly, it analyzes the legal regulation of the Catholic Church from the perspective of the Ecclesiastic Law of the Chilean State, as well as it proposes an interpretation regarding the legal situation of this church that takes aim at solving one of the most debated issues during the legislative process, whose effects lasts up to this day.

PALABRAS CLAVE

Personas Jurídicas, Derecho y Religión, Estatuto Jurídico de la Iglesia Católica KEYWORDS

Legal Persons, Law and Religion, Legal Regulation of the Catholic Church

\section{INTRODUCCIÓN}

Próximamente se cumplirán doce años desde la entrada en vigencia de la normativa legal que, aprobada en el año 2000, ha regulado bajo el principio de la igualdad jurídica, la constitución civil de las entidades religiosas en Chile ${ }^{1}$.

En efecto, la Ley No 19.638, conocida como Ley de cultos, vino a cambiar la situación precedente, que favorecía a la iglesia histórica y mayoritaria, asentando un nuevo orden jurídico aplicable a estas entidades, basado en el principio rector de la libertad religiosa, entendida como el derecho del hombre a relacionarse con Dios de acuerdo a los dictados de su conciencia, sin coacción de autoridad u otra persona y con la única restricción del respeto al orden público².

\footnotetext{
${ }^{1}$ Para profundizar en los contenidos de la ley $N^{\circ} 19.638$, su tramitación parlamentaria y el contexto material de su discusión, considérese Del Picó Rubıo, Jorge (Coord.), Ley de cultos y documentos complementarios, KAS/ICHEH, Santiago de Chile, 2000; Silva Cuevas, Luis Eugenio et alii. "Consideraciones históricas y jurídicas en torno a la Ley de Culto", Revista Humanitas 9, Separata VII, 1998; Salinas Araneda, Carlos "Las fuentes del Derecho eclesiástico del Estado de Chile", Revista de Derecho de la Universidad Católica de Valparaíso XXI, 2000, pp. 194 y ss.; ídem Lecciones de Derecho eclesiástico del Estado de Chile, Ediciones Universitarias de Valparaíso, Valparaíso, 2004, pp. 284-296; "Confesiones religiosas y personalidad jurídica en el Derecho del Estado de Chile", Anuario de Derecho eclesiástico del Estado, XVIII, 2002, pp. 151 y ss. Una evaluación del impacto de la ley, transcurridos diez años desde su entrada en vigor y enfocada desde diversas disciplinas jurídicas y considerando visiones religiosas mayoritarias y minoritarias en el país, es abordada en DeL PICó RuBıo, Jorge (Coord.), Derecho de la libertad de creencias, Abeledo Perrot, Santiago de Chile, 2010.

${ }^{2}$ Cfr. Del Pıcó Rubıo, Jorge, "La Ley de constitución jurídica de entidades religiosas: instituciones fundamentales", en Del Picó, Derecho, cit. nota n. 1, p. 9. Asimismo, considérese Salinas, Lecciones, cit.
} 
Sin perjuicio del objetivo central del legislador, en orden a igualar el status jurídico de las distintas confesiones religiosas con existencia legal en Chile, propósito abordado por el art. $2^{\circ 3}$ y reforzado en el art. $20^{4}$ de dicho cuerpo normativo, la ley $\mathrm{N}^{0} 19.638$ realizó una distinción fundamental entre las entidades preexistentes en el goce de la personalidad jurídica de derecho público y aquellas que en adelante manifestaran su pretensión de adquirirla, consideración que permitió brindar al proyecto el consenso que terminaría por facilitar su aprobación legislativa.

Dicha distinción, consagrada en el ya citado artículo 20, destrabó la tramitación legislativa en un momento en que parecía que el propósito de sus promotores sería abortado, sobre la base de establecer un sistema general de constitución jurídica para la obtención del reconocimiento estatal como personas de Derecho público, aplicable a todas las organizaciones y grupos religiosos que no gozaren de ella al momento de la entrada en vigor de la ley. Sin perjuicio de lo anterior, y sin pronunciarse expresamente sobre el controvertido tema del origen de la personalidad jurídica de derecho público atribuido a la Iglesia Católica ${ }^{5}$, también reconoció la preexistencia de esta calidad jurídica, respecto de aquellas entidades que, a la fecha de entrada en vigencia de la ley, ya gozaren de ella, vale decir, a la Iglesia Católica, apostólica y romana y a la Iglesia Ortodoxa, tributaria del Patriarcado de Antioquia, materia que revisaremos con mayor detalle en el apartado siguiente.

nota n. 1, pp. 87 y ss.; SALINAS, "Las fuentes", cit. nota n. 1, pp. 170-172. El marco constitucional, si bien aborda la libertad de creencias en el contexto de los derechos y libertades tuteladas, no explicita el contenido, lo que si realizará de un modo más desarrollado la LC, tanto en su dimensión individual como colectiva. Asimismo, el principio de libertad religiosa, fue promovido activamente como marco de la regulación en tramitación, tanto por las iglesias evangélicas como por la Iglesia católica. Así puede apreciarse en Comité de Organizaciones Evangélicas de Chile, "Observaciones formuladas por el Comité de Organizaciones Evangélicas a la indicación sustitutiva del proyecto de ley sobre la constitución jurídica de las iglesias", en Del Picó, Ley, cit. n. 1, pp. 65 y ss., para el primer caso, y Vial CorReA, Juan de Dios, "Intervención con motivo del foro sobre Ley de Culto", Revista Humanitas 9, Separata VII, 1998, p. 1, para la perspectiva de la Iglesia católica.

${ }^{3}$ Dispone el art. $2^{\circ}$ de la ley $N^{\circ} 19.638$ : "Ninguna persona podrá ser discriminada en virtud de sus creencias religiosas, ni tampoco podrán éstas invocarse como motivo para suprimir, restringir o afectar la igualdad consagrada en la Constitución y la ley".

${ }^{4}$ Dispone el art. 20, en su parte final: “...entidades que mantendrán el régimen jurídico que les es propio, sin que ello sea causa de trato desigual entre dichas entidades y las que se constituyan en conformidad a esta ley".

${ }^{5}$ Desde la vereda protestante, si bien deja abierta la puerta de la consideración de la Iglesia católica como persona jurídica de derecho público internacional, Lagos termina por concluir que, "lo cierto y realista, es que la práctica legal, vigente desde 1925 hasta la publicación, en el año 1999 de la Ley № 19.638, asentó una discutible personalidad jurídica de derecho público para la Iglesia católica, además de su calidad de persona de derecho internacional...". Vide Lagos Schuffeneger, Humberto, Chile y el mito del Estado laico, Icthus, Santiago de Chile 2005, pp. 11 y 14. 
En lo que respecta al propósito específico del presente trabajo, éste tiene por objetivo exponer el régimen jurídico especial que rige a las entidades religiosas con preexistencia histórica en Chile, precisando el marco normativo aplicable, fijando sus fuentes directas, determinando sus efectos y anticipando una solución coherente a las cuestiones interpretativas emergentes ${ }^{6}$.

Finalmente, cabe destacar que la reciente aprobación de la ley $N^{\circ} 20.500$, que modificó sustantivamente el régimen aplicable a la constitución de personas jurídicas de derecho privado sin fines de lucro, no alteró la regulación jurídica de la materia aquí tratada, efecto que sí está abierto a la discusión en el caso de las entidades comprendidas en el régimen general de constitución jurídica contemplado en la ley $N^{\circ} 19.638$.

\section{ANTECEDENTES}

El sistema jurídico chileno, al momento del restablecimiento de la institucionalidad democrática, consagraba una distinción básica en lo que a reconocimiento de la personalidad jurídica de las entidades religiosas se refiere.

Así, existían entidades regidas por el inciso $2^{\circ}$ del artículo 547 del Código Civil (CC), como la Iglesia católica y otras reguladas por el decreto supremo $N^{\circ} 110$, siendo las primeras reconocidas como personas jurídicas de derecho público y las segundas como personas jurídicas de derecho privado ${ }^{7}$. Las divergencias apreciables entre ambas calidades, sin restar por ello la debida importancia al factor diferenciador, son fundamentalmente simbólicas, dando cuenta principalmente de la distinta consideración social, histórica, política y, consiguientemente, jurídica, que la sociedad chilena prodiga a unas y otras.

En esta perspectiva, la consecuencia jurídica más relevante referida al goce de una y otra calidad, se aprecia en el momento de la extinción de la personalidad jurídica, toda vez que en el caso de las personas de derecho pública dicha declaración debe ser realizada mediante una ley, en tanto que en aquellas que gozan de personalidad de derecho privado sólo se requiere un decreto del presidente de la República, como ocurrió en el histórico caso

\footnotetext{
${ }^{6}$ Este trabajo completa una revisión analítica del régimen aplicable a las entidades religiosas en Chile, en el marco provisto por la ley $N^{\circ} 19.638$. Precedentemente, he abordado en su especificidad el régimen general dispuesto por la normativa y los principios informadores de la ley, en: "La Ley de constitución jurídica de entidades religiosas y la modelación del Derecho eclesiástico del Estado de Chile", Anuario de Derecho eclesiástico del Estado, XXVI, 2010, pp. 29-54; "El régimen de las personas jurídicas derivadas, Génesis y regulación de personas jurídicas derivadas en el marco previsto por la ley 19.638", en PIzARro Wilson, Carlos (Coord.), Estudios de Derecho Civil IV, LegalPublishing, Santiago de Chile 2009 y, finalmente, "El supuesto de objeción de la constitución jurídica de entidades religiosas", sometido actualmente a arbitraje en una revista especializada.
}

7 Así, Lyon Puelma, Alberto, Personas jurídicas, Ediciones Universidad Católica de Chile, 4a. edición ampliada, Santiago de Chile 2006, p. 244. 
de la disolución de la ex Colonia Dignidad, durante el gobierno del Presidente Aylwin.

Lyon Puelma, en concordancia con Alessandri, sintetiza la opinión de la doctrina civil históricamente predominante sobre la cuestión, enfatizando que, sin perjuicio que el CC dispone el orden de la materia en términos generales, "se debe concluir necesariamente que se refiere a la Iglesia Católica, Apostólica y Romana, puesto que, bajo la sola vigencia del Código civil, ésta era la única que podía existir por expresa disposición de la Constitución vigente en aquella época". La interpretación realizada por este autor, lo lleva a entender por iglesias a "las distintas subdivisiones de la Iglesia católica universal a las que el Derecho canónico reconoce personalidad..." y, extensivamente, por corporaciones religiosas aquellas a las cuales el Derecho canónico denomina religiones ${ }^{8}$.

Además de ser jurídicamente discutible, dicha distinción fue considerada injusta y discriminatoria por parte de las confesiones religiosas minoritarias existentes en el país, especialmente por la comunidad evangélica ${ }^{9}$, cuyos líderes bregaron por lograr una reforma del sistema, de manera tal que su normativa consagrara concluyentemente que tanto la personalidad jurídica como el procedimiento que antecede a su obtención sea regulado por la ley en forma general, sin discriminación alguna a favor de las iglesias con presencia histórica en el país.

El propósito reseñado se logró, en definitiva, por medio de la aprobación de la LC, cuyas disposiciones, en líneas generales, reconocen a las confesiones religiosas que así lo requieran, el derecho de constituir personas jurídicas de derecho público, con análogas facultades que aquellas entidades que ya gozaban de dicha calidad, como crear personas jurídicas con fines religiosos y acceder a franquicias tributarias.

Sin perjuicio de lo anterior, desde el inicio de la tramitación legislativa del proyecto de ley en 1993, un número importante de abogados, académicos, dirigentes políticos y parlamentarios vinculados a la Iglesia Católica manifestaron con vigor una perspectiva crítica hacia el contenido dispositivo del mismo, con especial detención en aquellos puntos en que percibían un detrimento de las prerrogativas históricamente reconocidas a la Iglesia, como la eventual intención de revisar la normativa aplicable a la luz del régimen general previsto en el proyecto. Lo anterior se tradujo en la presentación de sucesivas indicaciones efectuada por parlamentarios afines a la Iglesia Católica, tendientes a cautelar

\footnotetext{
${ }^{8}$ Ibídem, p. 244, en concordancia con Alessandri y Somarriva, en Alessandri RodríGuez, Arturo Somarriva Undurraga, Manuel, Curso de Derecho Civil (segunda edición redactada y puesta al día por Vodanovic, Antonio), Nascimento, Santiago de Chile 1945, Nascimento, p. 930. Véase también Salinas, "Las fuentes", cit. nota n. 1, pp. 194 y ss.

${ }^{9}$ Lagos califica al sistema aplicable a las confesiones evangélicas, como un régimen de tolerancia y no de igualdad. Ibídem, p. 27.
} 
el estatuto vigente que regía tanto a esta entidad religiosa como a la Iglesia Ortodoxa, procurando incorporar en el proyecto un expreso reconocimiento de la personalidad jurídica de derecho público de estas dos entidades, así como de su plena capacidad de obrar ${ }^{10}$.

El senador Hamilton sintetizó el propósito legislativo en la materia, recogido consensualmente por la Comisión de Constitución, Legislación, Justicia y Reglamento del Senado, destacando que, "lo que legítimamente impulsaron las iglesias evangélicas y recogieron los gobiernos de Aylwin y de Frei RuizTagle, a través de este proyecto, es la idea de otorgar un reconocimiento legal a las iglesias y confesiones que no lo tenían, a fin de que pudieran gozar de una personería [sic] de derecho público. En tanto, lo que las Iglesias Católicas y Ortodoxa han pedido, es que se respeten los estatutos jurídicos que las rigen y con los cuales han servido a la Nación"11.

El legislador, en definitiva y luego de una indicación sustitutiva cuyo contenido será abordado más adelante, asumió que tanto la Iglesia Católica como la Iglesia Ortodoxa, ya poseían existencia legal con goce de esta calidad jurídica, acuerdo que es recogido en el sentido indicado por el artículo 20 de la ley $N^{\circ}$ 19.638. De igual manera, el legislador ha permitido que las organizaciones religiosas que ya gozaban del reconocimiento estatal de su personalidad jurídica de derecho privado, puedan mantener dicha calidad, en tanto cumplan con los requisitos previstos en el Código Civil y en el decreto supremo № 110.

El citado artículo 20 de la ley $\mathrm{N}^{\circ} 19.638$ prescribe al efecto:

"El Estado reconoce el ordenamiento, la personalidad jurídica, sea ésta de derecho público o de derecho privado, y la plena capacidad de goce y ejercicio de las iglesias, confesiones e instituciones religiosas que los tengan a la fecha de publicación de esta ley, entidades que mantendrán el régimen jurídico que les es propio, sin que ello sea causa de trato desigual entre dichas entidades y las que se constituyan en conformidad a esta ley".

Esta norma, como se desprende de su lectura, traduce fielmente el propósito del legislador de no afectar los derechos adquiridos por las entidades religiosas que, al momento de la publicación de la ley $N^{\circ} 19.638$, ya gozaban de la

\footnotetext{
${ }^{10}$ Indicaciones de los senadores Sergio Bitar, Sergio Diez, Olga Feliú, Juan Hamilton, Hernán Larraín, Roberto Muñoz y Sebastián Piñera. Vide Senado de La República, Diario de Sesiones del Senado, Legislatura №340 ordinaria, sesión 10, de 6 de julio de 1999. Las aprensiones de los asesores legislativos de la Iglesia católica se ven fielmente reflejadas en las opiniones vertidas por Luis Eugenio Silva Cuevas, José Luis Cea Egaña y Jorge Precht Pizarro, en los aspectos histórico, constitucional y de derecho eclesiástico, respectivamente, en SiLva Cuevas, Luis Eugenio et alii, "Consideraciones históricas y jurídicas en torno a la Ley de Culto", Revista Humanitas 9, Separata VII, 1998. En especial, es muy ilustrativa la opinión de Precht, la cual puede ser apreciada extensamente en PreCht PizARRO, Jorge, "Un caso de mutación legislativa: la ley de iglesias", en SıIva, Consideraciones, cit. nota n. 10, pp. 12-18.
}

${ }^{11}$ Vide Det Picó, Ley, cit. nota n. 1, p. 86. 
calidad de personas jurídicas de derecho público. Se procuró, en definitiva, no alterar el reconocimiento de la personalidad jurídica y de la capacidad de goce y de ejercicio de la Iglesia Católica y de la Iglesia Ortodoxa, asumiendo, en definitiva, la existencia de la tutela constitucional respectiva, consagrada en el art. $19 \mathrm{~N}^{\circ} 24$ de la CPE ${ }^{12}$.

La deferencia del legislador tuvo plena justificación, toda vez que uno de los puntos expuestos en el debate y que dilató la aprobación de la ley en el Congreso, fue el temor expresado por algunos parlamentarios de religión católica, pertenecientes a distintos partidos políticos con representación en el Congreso Nacional, en orden a que la nueva ley pudiera afectar la situación jurídica vigente tanto de la Iglesia Católica como de la Iglesia Ortodoxa ${ }^{13}$. En concreto, la cuestión debatida se concentró en la primera redacción propuesta para el art. $6^{\circ}$ de la ley en tramitación, el cual afectaba los derechos adquiridos de ambas iglesias, al no reconocer de un modo adecuado a la realidad histórica el origen y el carácter de la personalidad jurídica que ya poseían en propiedad. De igual modo, constituía una fuente de inquietud, así percibida por los obispos de la Iglesia católica y por sus asesores legislativos, la incertidumbre emergente sobre la continuidad del reconocimiento de las prerrogativas eclesiásticas luego de la entrada en vigor de la futura ley, toda vez que su ejercicio aparecía cautelado sólo hasta el momento de su publicación ${ }^{14}$.

La oposición a esta pretensión se manifestó en forma abierta y frontal por parte de los representantes de las iglesias evangélicas, los que vieron en esta preocupación un nuevo intento destinado a preservar privilegios incompatibles con el principio de igualdad ante la ley. La resistencia ofrecida por estos sectores retrasó la aprobación del proyecto al menos por dos años, pero finalmente primó la voluntad de entendimiento y la ley incorporó una norma de compromiso en el

\footnotetext{
${ }^{12}$ Cfr. Cea Egaña, siguiendo a Diez Urzúa, en Cea Egaña, José Luis, "Mérito Constitucional del Proyecto de Ley sobre Organizaciones Religiosas", Revista Humanitas 9, Separata VII, 1998, p. 38. Para una profundización de la CPE de 1980 como fuente del Derecho eclesiástico del Estado de Chile, considérese también la opinión de Salinas, en un artículo coetáneo con la entrada en vigor de la ley $N^{\circ} 19.638$, en Salinas, "Las fuentes", cit. nota n. 1, pp. 170 y ss.

${ }^{13}$ Vide Conferencia Episcopal de Chile, Declaración Pública de la Conferencia Episcopal de Chile, 25 de mayo de 1999. En las conclusiones finales, la declaración expresa lo siguiente. "Los obispos católicos de Chile pedimos a la comunidad nacional y a las autoridades, que se otorgue a las demás confesiones religiosas el estatuto jurídico que necesiten, pero respetando plenamente la intangibilidad de los derechos que ya poseen, natural y legalmente, las iglesias, cualquiera que estos sean. Y que, como consecuencia, en su caso, se preserve el régimen jurídico propio con el que han contado en nuestro país tanto la Iglesia católica, que se rige por el Código de Derecho canónico y otras leyes acordadas conforme a él, como la Iglesia ortodoxa de Antioquía en Chile, declarándolo así la ley de una manera clara y explícita".

${ }^{14}$ Cfr. Palet Claramunt, Enrique, "Exitosa porfía católica y evangélica", en Del Picó, Ley,, cit. nota n. 1 , p. 140.
} 
art. 20 del proyecto, con una redacción que, a la vez que cauteló los derechos adquiridos de las iglesias históricas, consagró que tal reconocimiento no podía ser causa de un trato desigual entre las entidades antiguas y las constituidas en conformidad a la nueva ley ${ }^{15}$. Con la inclusión de esta normativa, la ley pudo ser aprobada en forma unánime, con el concurso de parlamentarios de los diversos partidos políticos ${ }^{16}$.

\section{Efectos derivados del artículo 20 de La ley Nº 19.638}

Las disposiciones de la LC, salvo aquellas comprendidas en los capítulos III y $\vee$ y que abordan la constitución y extinción de las entidades religiosas que se acojan a sus normas, se aplican por igual a todas las entidades religiosas con existencia legal en Chile. Sin perjuicio de ello, la disposición final de la ley se aplica exclusivamente a las entidades religiosas con preexistencia legal como personas jurídicas de derecho público, vale decir las iglesias Católica y Ortodoxa ${ }^{17}$.

La norma comprendida en la disposición final de la ley $\mathrm{N}^{\circ} 19.638$, cuyo origen y sentido hemos desarrollado en el apartado precedente, generó dos efectos principales relacionados con las entidades religiosas con personalidad jurídica preexistente al momento de la entrada en vigor de la LC, referidos el primero al reconocimiento de la personalidad jurídica y, el segundo, al reconocimiento del derecho a mantener inalterado el régimen jurídico propio -que se traduce principalmente en el ordenamiento interno de la entidad-con el cual contaban al momento de la publicación de la LC.

Se agrega a los efectos ya indicados, una prevención legal ante la ocurrencia de posibles tratos desiguales respecto de las entidades que gozan de una personalidad jurídica diferente, cuya eventual utilidad revisaremos más adelante,

\footnotetext{
${ }^{15}$ Vide art. 20 ley $\mathrm{N}^{\circ} 19.947$.

${ }^{16}$ La posición de la Iglesia católica y de sus reparos jurídicos frente al Proyecto de de Ley sobre Constitución Jurídica de las Iglesias, puede ser apreciada en Siıva Cuevas, Luis Eugenio et alii, "Consideraciones históricas y jurídicas en torno a la Ley de Culto", Revista Humanitas 9, Separata VII, Santiago de Chile, 1998. En especial, considérese PRECHT PIZARRO, Jorge Enrique, "Un caso de mutación legislativa: la ley de iglesias", pp. 8-18.

${ }^{17}$ Coincido en general con lo expuesto por Salinas, divergiendo en la aplicación del capítulo IV, referido a la regulación de los aspectos patrimoniales, que este autor no incluye. Estimamos que la normativa aplica en general, cualquiera sea el origen y naturaleza de la personalidad jurídica con que cuentan las entidades, toda vez que se trata de principios generales referidos al principio de igualdad jurídica, el sometimiento a la legislación común en el ámbito patrimonial y al régimen de exenciones, dejando en el ámbito de la autonomía de cada entidad los aspectos administrativos (cfr. SALINAS, "Las fuentes", cit. nota n. 1, p. 197). Una perspectiva completa sobre los efectos del artículo 20, puede ser también apreciada en PRECht PIZARRo, Jorge, 15 Estudios sobre Libertad Religiosa en Chile, Ediciones Universidad Católica de Chile, Santiago de Chile, 2006, capítulo VI.
} 
al igual que el carácter obligatorio o facultativo que tiene la posible mutación de la naturaleza jurídica de la personalidad ya reconocida. Revisaremos en particular cada uno de estos efectos.

\subsection{Reconocimiento de la personalidad jurídica}

En primer lugar, el artículo 20 reconoce la personalidad jurídica de la cual gozaban las entidades religiosas preexistentes a la LC, sea ésta de derecho público o de derecho privado, implicando para las primeros una ratificación del régimen jurídico privilegiado utilizado y, para las segundos, el derecho de mantener la personalidad jurídica de derecho privado -regida por las normas vigentes en la materia- si así lo estimaren a la luz de la defensa de sus propios intereses.

En el primer caso quedan incluidas las iglesias católica y ortodoxa, en tanto que en el segundo supuesto se incluyen todas las demás entidades religiosas que poseían personalidad jurídica de derecho privado, entre las cuales cabe contar a la mayoría de las iglesias evangélicas.

Por tanto, la ley no altera la vigencia de la calidad jurídica de las entidades religiosas, motivo por el cual las agrupaciones que contaban con personalidad jurídica de derecho público, no han debido realizar trámite alguno para validar o renovar el reconocimiento jurídico con el cual ya contaban, no existiendo solución de continuidad. Lo mismo ocurre con las entidades con personalidad jurídica de derecho privado, salvo que deseen mutar la naturaleza jurídica corporativa y constituirse como persona jurídica de derecho público, objetivo para el cual deberán seguir el procedimiento contemplado en el art. 10 de la ley $\mathrm{N}^{\circ} 19.638$.

Una consecuencia obvia del reconocimiento de la personalidad jurídica o de su vigencia, es la extensión al reconocimiento de la plena capacidad, lo que se puede entender como una consecuencia de la persistencia del recelo histórico de las confesiones minoritarias hacia las leyes dictadas en la materia, lo que explica la reiteración en la que incurre el legislador.

\subsection{Reconocimiento del ordenamiento jurídico preexistente}

En segundo lugar, la ley reconoce el ordenamiento jurídico de las entidades religiosas preexistentes al año 1999, vale decir, el conjunto articulado de normas jurídicas vigentes en dichas confesiones religiosas, y que responden a la necesidad de organización de tales comunidades religiosas, con vistas a su inserción e interacción con la sociedad y el Estado. La facultad de ordenar normativamente la vida de la entidad, es accesoria de la personalidad ya reconocida.

La disposición final de la ley $N^{\circ} 19.638$, refiere explícitamente al reconocimiento de un "ordenamiento" jurídico, concepto que requiere precisión. En efecto, 
la distinción efectuada por el legislador significa que si bien se reconoce en todos los casos la personalidad jurídica de la entidad religiosa, este reconocimiento no se extiende necesariamente a cualquier ordenamiento. Para que ello ocurra, se requiere que el ordenamiento sea anterior a la fecha de publicación de la ley y, además, que éste posea las características que distinguen a un orden jurídico reconocido como tal, vale decir, que constituya un conjunto sistemático de prescripciones de conducta vigentes y aplicadas en el interior de la colectividad, que rigen su vida interna con carácter imperativo y no meras instrucciones verbales o normas dispersa, en textos de disímil naturaleza, funcionalidad e importancia.

La relevancia de esta precisión se justifica, atendido el carácter de requisito imprescindible que la ley asigna a la existencia de un ordenamiento previo, para reconocer la atribución de crear personas jurídicas derivadas de la entidad matriz. Si el ordenamiento no existe al momento de la publicación de la ley, nada obsta para redactarlo con posterioridad y luego solicitar su reconocimiento en carácter de tal, al Ministerio de Justicia, mediante una modificación estatutaria, en la cual se indique que el ordenamiento cuyo texto se adjunta, es parte integrante del estatuto que fue acompañado en su oportunidad, al solicitar la inclusión de la entidad en el registro del Ministerio de Justicia.

La aplicación de esta perspectiva a las entidades religiosas contempladas en la ley, admite los siguientes comentarios.

Por lo pronto, la ley reconoce la validez plena y la vigencia de los ordenamientos jurídicos de derecho eclesiástico particular, existentes en el momento previo a la aprobación de la Ley de cultos, de todas las entidades religiosas, independientemente de la naturaleza jurídica pública o privada de su personalidad. Esta declaración es aplicable a todas las entidades religiosas precedentemente constituidas y reconocidas por el Estado, sin considerar la diversa naturaleza jurídica de su personalidad, pero interesa especialmente a la Iglesia católica y a la Iglesia ortodoxa, según lo ya anunciado.

En el caso de la Iglesia Católica, el régimen canónico vigente no es alterado, confirmándose que la erección de las personas jurídicas canónicas y su regulación se rige por dicho Código, razón por la cual una vez creadas en dicha sede eclesiástica y autentificado dicho acto por el notario eclesiástico, el Estado las recepciona sin más trámite y reconoce su existencia. En la práctica, ello ocurre del modo indicado, aún cuando algunos funcionarios públicos que, antes de la entrada en vigor de la LC, lo aplicaban de manera automática, ahora tienden a consultar la validez del procedimiento cuya vigencia se proclama por parte de los interesados.

Respecto de la especificidad de las personas jurídicas que el Estado reconoce, cabe indicar que se comprenden aquí todas aquellas que la entidad eclesiástica matriz declare como formalmente existentes de acuerdo a su ordenamiento jurídico particular, amparado para ello en la autonomía reconocida 
a las entidades religiosas en esta materia según lo dispuesto por el art. $7^{\circ}$ de la $\mathrm{LC}^{18}$. Así, en el caso de la Iglesia católica, se incluyen las congregaciones y comunidades religiosas, las diócesis y las parroquias, prelaturas personales y territoriales, el ordinariato castrense, los vicariatos apostólicos y las prefecturas apostólicas, debiendo incluirse tanto las personas jurídicas canónicas públicas como otras derivadas que cumplan fines religiosos indirectos, como la beneficencia pública, aun cuando comparto que, por seguridad y conveniencia de las propias iglesias, es preferible que la constitución de éstas se realice con base en el ordenamiento civil estricto ${ }^{19}$, afirmación que adquiere mayor fuerza con la reforma introducida al procedimiento legal de constitución de asociaciones sin fines de lucro, recientemente promulgada ${ }^{20}$.

\subsection{Igualdad de trato por parte del Estado a las entidades religiosas, sean de derecho público o de derecho privado}

En tercer lugar, la ley no establece diferencias en la consideración o trato por parte de los agentes públicos, entre una entidad religiosa de Derecho público y una entidad religiosa de Derecho privado. Al revestir un carácter voluntario, la decisión de modificar los estatutos de la entidad determina que las diferencias entre unas y otras dependan exclusivamente de la calidad jurídica que posean, como cualquier asociación civil ante el Derecho.

Lo anterior tiene un origen histórico, derivado del interés de los promotores de la reforma de evitar la consagración de nuevas formas de discriminación basadas en el carácter mayoritario o minoritario de las entidades, atendiendo a la preferencia manifestada por los ciudadanos, que pudieran implicar arbitrariedades por parte de la autoridad. Incidía en esta prevención legalmente recogida, el interés manifestado por parte de algunas entidades, en orden a evitar perjuicios emergentes que pudieran derivarse de la adopción de una decisión de no innovar en el reconocimiento vigente de la entidad como persona jurídica de derecho privado. La justificación de esta decisión por parte de los líderes de las comunidades religiosas enfrentadas a esta disyuntiva, radicaba en las dificultades que acompañaban el proceso de traspaso de los bienes eclesiásticos, toda vez que un número importante de entidades evangélicas mantenían una confusión

\footnotetext{
${ }^{18}$ Dispone el art. $7^{\circ}$ de la ley $N^{\circ} 19.638:$ "En virtud de la libertad religiosa y de culto, se reconoce a las entidades religiosas plena autonomía para el desarrollo de sus fines propios y, entre otras, las siguientes facultades:...b) Establecer su propia organización interna y jerarquía; capacitar, nombrar, elegir y designar en cargos y jerarquías a las personas que correspondan y determinar sus denominaciones".

${ }^{19}$ Cfr. Precht Pizarro, Jorge, "La Iglesia católica y su auto percepción", en Del Picó, Derecho, cit. nota n. 1, p.184

${ }^{20}$ Ley $N^{\circ} 20.500$, de 4 de febrero de 2011, publicada en el DO de 16 de febrero de 2011.
} 
de los patrimonios del pastor -sujeto jurídico individual-y de la iglesia -sujeto jurídico colectivo- incompatible con la dignidad institucional pregonada por las agrupaciones religiosas y promovida por el legislador.

Sin perjuicio de lo anterior, las diferencias derivadas de la diversa naturaleza legal, no pueden ser consideradas discriminatorias ni menos arbitrarias. El estatuto de derecho público, sin duda alguna, era considerado ventajoso para la Iglesia católica, y discriminatorio para las confesiones minoritarias. Sin embargo, estas entidades, que se sentían discriminadas, deseaban ser partícipes de estos beneficios y, en caso alguno, postulaban su eliminación. En definitiva, lo que se buscaba afanosamente era el reconocimiento del derecho a gozar de iguales beneficios.

El propósito perseguido se consiguió finalmente, de la mano de una legislación que niveló el derecho de optar a beneficios públicos, pero al nivel que ya tenían reconocido las iglesias católica y ortodoxa, y no al grado inferior del cual gozaban todas las demás. Por ello, mal podría entenderse como discriminatorio en términos negativos, que el nuevo estatuto al cual ahora pueden optar todas las entidades religiosas, consagre determinados beneficios ligados a esta calidad jurídica, de la cual pueden participar todas aquellas que cumplan con los requisitos legales generales, como ya lo han hecho más de mil quinientas entidades religiosas. Así, por ejemplo, la Ley $\mathrm{N}^{\circ} 19.947$, sobre Matrimonio Civil, ha reconocido el derecho de celebrar matrimonios religiosos con efectos civiles a las entidades que gozan de personalidad jurídica de derecho público, y no a las que posean personalidad jurídica de derecho privado. Lo propio, en igual sentido, consagra la propia LC al disponer la posibilidad de constituir personas jurídicas derivadas de la entidad matriz, sólo respecto de las personas jurídicas de derecho público ${ }^{21}$.

\subsection{Carácter voluntario del cambio de la naturaleza jurídica de la personalidad de la entidad religiosa}

En cuarto lugar, la ley permite a los miembros de una entidad religiosa instituida bajo las normas del decreto supremo $N^{\circ} 110$, mantener dicha calidad, si así lo estiman necesario o conveniente en atención a su particular realidad eclesiástica, no exigiéndose la obligatoriedad de una reforma estatutaria si no hay mutación de la forma jurídica. En esta línea interpretativa, se asume que el derecho a modificar su régimen estatutario, desde luego, lo tienen las entidades religiosas que se constituyan en conformidad a la ley y, por tanto, las modificaciones a las normas internas se realizarán en conformidad a las disposiciones de sus propios estatutos.

Cabe consignar que la entidad religiosa, como derivación de esta facultad, puede introducir modificaciones a las normas internas, con plena autonomía,

${ }^{21}$ Vide art. $8^{\circ}$ ley $\mathrm{N}^{\circ} 19.638$. 
sin perjuicio de estar sujeta a las mismas restricciones vigentes establecidas para la constitución jurídica de la entidad, como las disposiciones que aseguran el libre ingreso y retiro de los miembros de la organización religiosa.

Finalmente, la regulación del proceso de reforma se deberá contemplar en los mismos estatutos ${ }^{22}$.

\section{ReCONOCIMIENTO LEGAL DE LA PERSONALIDAD JURídiCA DE DERECHO PÚBLICO preEXISTENTE de la IGlesia Católica y de la IGlesia Ortodoxa}

La norma contenida en el artículo 20 de la LC, como ya se ha adelantado, adquiere especial relevancia en el caso de las iglesias Católica y Ortodoxa, respecto de las cuales el legislador zanjó definitivamente cualquier cuestión pendiente o debatida sobre la naturaleza y origen de su personalidad jurídica, particularmente en el caso de la Iglesia católica, brindando un definitivo reconocimiento a sus respectivos ordenamientos y a su calidad jurídica. Sin constituir este un propósito de los impulsores del proyecto de ley, ni siquiera remotamente, es indiscutible que a la luz de sus resultados prácticos respecto de la comunidad religiosa mayoritaria, se ha convertido en uno de los efectos más relevantes de la LC.

En lo que respecta a la apreciación de la situación jurídica de la Iglesia Católica, en el período previo a la entrada en vigor de la ley $N^{\circ} 19.638$, cabe constatar que ni el origen ni la formalización de su reconocimiento público como persona de derecho público concitaban consenso, ni en la doctrina ni entre los parlamentarios abocados a su estudio, pues al margen de la evidencia de su consideración efectiva por parte del Estado de Chile, hecho reconocido incluso por parte de la comunidad protestante ${ }^{23}$, la formalidad del origen de dicho reconocimiento lindaba en la confusión, brindando una base útil a los detractores de la existencia de un estatuto especial de la Iglesia Católica, para afirmar que la entrada en vigor de la CPE de 1925 había eliminado el privilegio concedido por la CPE de 1833 y recepcionado civilmente en el CC $^{24}$.

\footnotetext{
${ }^{22}$ Cfr. Zaldívar Larraín, Andrés, "Intervención del señor Presidente del Senado, don Andrés Zaldívar Larraín, en el Proyecto sobre constitución jurídica y funcionamiento de iglesias y organizaciones religiosas. Constancia sobre permanencia del régimen jurídico y estatutos de las entidades existentes", en Del Picó, Ley, cit., nota n. 1, p. 90.

${ }^{23}$ Vide Rodríguez Sepúlveda, Álvaro, "La personalidad jurídica de las iglesias en Chile", en Del Picó, Ley, cit. nota n. 1, pp. 145 y 146.

${ }^{24}$ La situación indicada es expuesta con notable sinceridad por Luis Eugenio Silva, al indicar que como consecuencia de la separación entre la Iglesia y el Estado en 1925, "Ia Iglesia pasó, a pesar de que no se firmó el concordato, como se dirá, a ser concebida y respetada como lo que siempre había sido: como persona jurídica de derecho público". Ratificará esta visión, en el mismo texto, resaltando que, "para poder entender lo que hoy día se discute [la LC], esto es, el estatuto, las condiciones, las características de lo que la Iglesia católica es en Chile, no se puede dejar de considerar la dimensión
} 
Lo cierto, como lo reconoce Salinas, siguiendo en esta lectura a Oviedo, es que luego de la amistosa separación del Estado y la Iglesia en $1925^{25}$, no se celebró nunca el concordato contemplado en las negociaciones, justificando aquella omisión en las limitaciones temporales derivadas de la urgencia por contar con una nueva constitución política, en la perspectiva de prioridades asumidas por el presidente Arturo Alessandri Palma, y en lo innecesario de plantear un concordato de amplia regulación jurídica entre la Santa Sede y Chile, atendiendo la improbabilidad de una alteración institucional que pudiera afectar el régimen legal de la Iglesia. Como sancionaba el Obispo Cavada, "utilidad habría, pero no verdadera necesidad", seguramente basado en la inexistencia histórica de un concordato entre la Santa Sede y Chile, y la correcta relación entre los poderes institucionales y la Iglesia ${ }^{26}$. Una interpretación extensiva, expuesta por Precht para justificar la existencia de un concordato sustantivamente hablando, aunque carente de la formalización requerida y de un soporte documental específico, no es suficientemente persuasiva, siguiendo en esta apreciación a Navarro Floria ${ }^{27}$.

El marco jurídico expuesto por los defensores del estatuto jurídico vigente de la Iglesia católica, en ausencia de concordato, fue el reconocimiento explícito por parte del Estado de Chile del carácter de sujeto internacional de Derecho público de la Santa Sede, en lo cual coinciden tanto Precht como Salinas, concluyendo ambos autores en considerar derechamente la vigencia de dicho reconocimiento, tesis a la cual se plegaron parlamentarios con cercanía a la Iglesia Católica ${ }^{28}$. En particular, Salinas resalta que la situación jurídica de la

histórica". En la perspectiva precedente, concluye Silva, “...si bien la historia como tal y en puridad no crea un derecho, de alguna manera ratifica las formas jurídicas con las cuales la Iglesia Católica vivió en el siglo XVI, en el siglo XVII, durante el siglo XVIII y el siglo XIX y hasta la mitad de 1925" (SIIVA Cuevas, Luis Eugenio, "Dimensión histórica del problema", Revista Humanitas 9, Separata VII, 1998, cit., p. 7). En contrario, afirmando indubitadamente el carácter de persona jurídica de derecho público durante la vigencia de las constituciones políticas de 1833, 1925 y 1980, considérese PRECHT PIZARRO, Jorge, Derecho eclesiástico del Estado de Chile, Santiago de Chile 2001, Ediciones Universidad Católica de Chile, p. 155. En la perspectiva protestante, vide Lagos, Chile, cit. nota n. 5, p. 14.

${ }^{25}$ Cfr. Del Pıcó Rubıo, Jorge, Derecho matrimonial chileno, Abeledo Perrot, Santiago de Chile 2010, pp. 20 y 21.

${ }^{26}$ SALINAS, "Las fuentes", cit. nota n. 1, 184 y 185 . Idem, "Confesiones religiosas y personalidad jurídica en el derecho del Estado de Chile", en Anuario de Derecho Eclesiástico del Estado, XVIII, 2002, p. 96 y ss.

${ }^{27}$ Navarro Floria, Juan, Acuerdos y concordatos entre la Santa Sede y los países americanos, Editorial de la Universidad Católica Argentina, Buenos Aires 2011, p. 31.

${ }^{28}$ Respecto de la posición sustentada por Precht sobre los acuerdos concordatarios y la Constitución chilena de 1925, y la personalidad jurídica de la Iglesia Católica y de los entes eclesiásticos católicos ante el Derecho del Estado de Chile, vide PRECHT, cit. nota n. 24, pp. 83-198. Asimismo, considérese las opiniones de Luis Eugenio Silva, Jorge Precht Pizarro y José Luis Cea Egaña, en Revista Humanitas, cit., nota n. 16. 
Iglesia católica difiere sustancialmente de la que caracteriza a las demás iglesias y confesiones religiosas con presencia en Chile, toda vez que, a su juicio, es la única que goza del estatuto de persona jurídica de Derecho internacional y que, por tanto, se encontraría habilitada para celebrar este tipo de acuerdos con el Estado de Chile ${ }^{29}$.

Sobre el punto, mantenemos nuestra opinión sobre la precariedad jurídica, luego de la entrada en vigor de la CPE de 1925 y atendida la historia de la discusión del Constituyente de 1980, sobre el fundamento para alegar la existencia indubitada del reconocimiento legal de la personalidad jurídica de la Iglesia católica en el carácter pretendido. Descartada la existencia de concordato que sirva de base para una afirmación en el sentido indicado ${ }^{30}$, subsiste, esta vez con base, la duda respecto de la extensión del reconocimiento brindado a la Santa Sede a la Iglesia católica chilena. En efecto, si bien no cabe duda respecto del carácter de sujeto internacional de Derecho público que tiene ante el Estado de Chile la Santa Sede, no ocurre lo mismo con la Iglesia Católica, la que enmarcada en las últimas dos constituciones políticas, entró en terreno poco firme, lo que por cierto se habría solucionado con la oportuna discusión y suscripción pacticia del concordato respectivo, al momento de la discusión de la separación entre la Iglesia y el Estado en los prolegómenos de 1925. En definitiva, superando o sintetizando la situación precedente, no cabe duda alguna que la ley $\mathrm{N}^{\circ} 19.638$, en forma colateral a su restringido propósito original, zanjó definitivamente la cuestión, consagrando el reconocimiento esta vez en sede legal de la personalidad jurídica de derecho público de la Iglesia Católica chilena ${ }^{31}$.

Volviendo a la discusión contemporánea del proyecto de ley de entidades religiosas, en la década de 1990 y en posiciones cercanas a la Iglesia Católica, cabe destacar la opinión expresada por el Senador Juan Hamilton, quien señaló: "La situación de la Iglesia Católica -por su historia, desde la Conquista hasta nuestros días; por su naturaleza universal, regida por el Derecho canónico, la legislación más antigua del mundo, y por su consagración constitucional, por acuerdo entre el Estado de Chile y la Santa Sede, para producir en la Constitución de 1925 la separación de la iglesia del Estado- es diferente o desigual respecto de las demás confesiones religiosas, motivo por el cual no es arbitrario el reconocimiento de esa situación. Así lo sostiene, por lo demás, el ex Presidente

\footnotetext{
${ }^{29}$ Cfr. Salinas Araneda, Carlos, Lecciones de Derecho eclesiástico del Estado de Chile, Ediciones Universitarias de la Universidad Católica de Valparaíso, Valparaíso, 2004, pp. 240-251. Asimismo, SAlinas Araneda, Carlos, "Las fuentes del Derecho eclesiástico del Estado de Chile", cit., nota n. 1, pp. 180 y ss.

${ }^{30}$ Considérese, para basar esta afirmación, NAVARRO, Acuerdos, cit. nota n. 27, 29-32.

${ }^{31}$ Sobre la materia, considérese especialmente, además del precedente artículo de Salinas, ídem, Lecciones, cit. nota n. 29, pp. 263 y ss.
} 
Aylwin en el mensaje del proyecto, citando precedentes de la Corte Suprema de Justicia"32.

El problema que enfrentó la discusión de la LC durante toda su tramitación en la perspectiva de la Iglesia católica, fue lograr un acuerdo político que permitiera preservar el reconocimiento de la personalidad y del ordenamiento jurídico, obtenidos luego del extenso período que comprendió la confrontación entre la Iglesia y los sectores laicistas en Chile, hasta el acuerdo constitucional de 1925. En definitiva, se trataba de concordar una fórmula legal que armonizara la preservación del estatuto jurídico de la Iglesia Católica con las legítimas pretensiones de igualdad jurídica de las entidades religiosas agrupadas en el $\mathrm{COE}$, cuya realización efectiva era apoyada oficialmente por la Conferencia Episcopal de Chile ${ }^{33}$.

La aprobación de una indicación sustitutiva, concordada entre el Congreso y el Ejecutivo, resolvió definitivamente la cuestión, dejando claramente establecido el respeto del estatuto preexistente de ambas entidades religiosas y la prevención en torno a que tal reconocimiento no constituiría una causa de trato desigual entre dichas entidades y aquellas que se constituyeran en conformidad a las normas de la nueva ley. Esta es, en definitiva, la explicación de la redacción de la norma del art. 20, en lo pertinente.

El artículo 20 zanjó definitivamente, por la vía legal, una discusión de larga data, respecto del reconocimiento de la calidad jurídica de la Iglesia Católica por parte del Estado de Chile. Con la vigencia del artículo 20, se entiende reconocida la calidad de persona jurídica de Derecho público nacional de la Iglesia Católica, sin perjuicio del reconocimiento en el ámbito propio del Derecho Internacional Público de la calidad jurídica de la Santa Sede y la consiguiente calificación jurídica de las relaciones interestatales ${ }^{34}$.

\footnotetext{
${ }^{32}$ Vide Del Picó, ley, cit. nota n. 1, p. 83

${ }^{33}$ Cfr. Precht Pizarro, Jorge, La Iglesia católica: su auto percepción y la Ley No 19.638, en Del Picó, Derecho, cit. nota n. 1, p. 183. En el mismo sentido, véase PrECHT, "Un caso", cit. nota n. 16, p. 9, y Palet, "Exitosa porfía católica y evangélica", en Del PICó, Ley, cit. nota n. 1, pp. 139-141. La posición oficial de la Conferencia Episcopal de la Iglesia católica de Chile, consta en la Declaración pública de 25 de mayo de 1999, la cual en sus números 2 y 3 señala lo siguiente: "La Conferencia Episcopal está de acuerdo y no se opone a la existencia de leyes que permitan a las Iglesias evangélicas y otras confesiones religiosas, obtener del Estado el reconocimiento, la personalidad y el ordenamiento jurídico que cada una de ellas necesite para desarrollar su misión en Chile, ya sea con fórmulas del derecho público, derecho privado o mixtas. La Iglesia Católica tampoco tiene objeciones a que el estado conceda derechos similares a los que ella posee a otras confesiones religiosas que cumplan con los debidos requisitos. Es función del Estado velar por el bien común, garantizar la libertad religiosa y de culto y dar a cada una de estas confesiones lo que le corresponde, sin perjudicar a las demás".

${ }^{34}$ Una exposición en profundidad sobre la personalidad jurídica de la Iglesia católica, propósito que excede a este trabajo, puede ser apreciada en SALINAS, Lecciones, cit. nota n. 1, pp. 263-280 y, precedentemente, ídem, "Confesiones religiosas y personalidad jurídica en el Derecho del Estado de
} 
Asimismo, el Derecho canónico, como estatuto propio de la Iglesia Católica chilena, reafirma su validez ante el Derecho chileno, dejando abierta la discusión respecto de la concordancia y ámbitos de intersección, colisión o exclusión con el ordenamiento jurídico nacional ${ }^{35}$, particularmente con el nuevo Derecho matrimonial instaurado por la ley $N^{\circ} 19.947$ y la cuestión jurisdiccional y de competencias surgida con ocasión del caso Karadima, aún pendiente de resolución ${ }^{36}$. Las entidades pertenecientes a la Iglesia que, al momento de la entrada en vigor de la LC, gozaban de personalidad jurídica canónica, la conservan en plenitud, acreditando su existencia mediante certificación de la autoridad eclesiástica competente ${ }^{37}$.

Chile", Anuario de Derecho Eclesiástico del Estado, XVIII, 2002, pp. 96-138. Asimismo, considérese PRECHT, Derecho, cit. nota n. 24, pp. 133-198.

${ }^{35}$ Con ocasión de los casos públicamente conocidos de faltas cometidas por sacerdotes, la Conferencia Episcopal, junto con acordar el procedimiento en la Iglesia aplicable a estos casos, marcó una clara posición sobre el régimen jurídico vigente y la competencia civil en la materia. Así, junto con declarar que la Iglesia respeta y promueve el ejercicio de la justicia, reiteró que, "el régimen que rige en Chile es de separación entre la Iglesia y el Estado", complementando con la afirmación de la idea que los tribunales son diversos, al igual que diferentes son los deberes y la configuración de los delitos y el establecimiento de las penas, todo ello de acuerdo al Derecho de cada sociedad, la civil y la religiosa. Finalmente, marcando claramente una doctrina sobre la materia, sanciona que los miembros de la Iglesia no pueden negarse a colaborar con los tribunales [justicia civil] cuando son requeridos, "salvo que el juez exigiera algo contrario a la ética, o contra el ordenamiento jurídico propio que el derecho chileno reconoce a la Iglesia Católica (Art. 20 de la ley 19.638)". Cfr. ConferenCIA EPISCOPAL DE CHILE, Comunicado de prensa sobre la actitud de de la Iglesia Católica en Chile ante los abusos contra menores cometidos por un clérigo o un religioso, 25 de Abril de 2003. Posteriormente, el 15 de mayo del mismo año, el vocero de la Conferencia Episcopal, Enrique Palet, en entrevista al Diario El Mercurio de Santiago, reiteró el fundamento brindado por el artículo 20 de la LC, al régimen especial que rige las actuaciones de la Iglesia en Chile, basado en el Derecho canónico (EL MerCuRIO, jueves 15 de mayo de 2003, cuerpo c, p. 9).

${ }^{36}$ Sobre la materia, la $85^{\text {a }}$ Asamblea Plenaria de la Conferencia Episcopal de Chile, Ilevada a cabo en abril de 2003, se pronunció sobre las graves faltas que constituyen delitos contra el sexto mandamiento, cometidas por un clérigo o un religioso con menores de 18 años, afirmando claramente que la denuncia ante la autoridad civil es un derecho de las víctimas y cuyo ejercicio debe ser respetado. De igual modo, concluyeron los obispos, "el hecho de pertenecer a la Iglesia, aun a su jerarquía, no hace que se pierdan ni los derechos ni los deberes de ser ciudadano", razón por la cual, "nada exime a un clérigo o a un religioso de responder por sus actos a la justicia civil". Cfr. CONFERENCIA EPISCOPAL DE CHILE, cit. nota n. 36.

${ }^{37}$ Sobre la materia y su regulación canónica, remítase al Libro II del Código de Derecho canónico (CIC). Para su apreciación comentada, considérese GutiéRrez, José Luis, "Comentarios a los cc. 294-411", en Instituto Martín de Azpilcueta, Código de Derecho canónico, quinta edición revisada y actualizada, Ediciones Universidad de Navarra, Pamplona 1992, pp. 160 y ss.; CENALMOR, Daniel y MIRAS, Jorge, El Derecho de la Iglesia, CELAM/EUNSA, Quito, 2004, pp. 147-318; Morales Galindo, Ricardo, Posición jurídica de las asociaciones de fieles en el derecho chileno, Orden de la Merced, Santiago de Chile 2000. Otra perspectiva sobre el estatuto jurídico de las organizaciones católicas, en CeLIS BRUNET, Ana María, "Iglesias y Estado en la República de Chile", en Navarro FloriA, Juan (Coord.), Estado, derecho y religión en América Latina, Marcial Pons, Madrid 2009, pp. 133-137. 
La entrada en vigor de la LC no involucra cambios en la consideración pública de su institucionalidad propia, sin perjuicio que, ante eventuales colisiones futuras con decisiones de la autoridad pública o conflictos de interés con otras entidades, el marco general provisto en materia de reconocimiento y tutela de la libertad religiosa contenido en el Capítulo II de la ley es enteramente aplicable. En lo que respecta a las situaciones anteriores a su entrada en vigor, esto es en octubre de 1999, "se rigen por el ordenamiento que las recepcionó conforme al artículo 20 de la ley $N^{\circ} 19.638^{\prime \prime 38}$.

Finalmente, como lo resalta Salinas, "la personalidad jurídica de derecho público de estas entidades puede ser suprimida por el Estado de Chile, pero para ello es necesaria una Ley de la República" ${ }^{\prime \prime 2}$. Cabe destacar sobre este punto que, con posterioridad, este mismo autor al distinguir el estatuto de la Iglesia Católica respecto del que rige a la Iglesia Ortodoxa, marca la diferencia indicando que la primera entidad, "tiene reconocimiento constitucional, lo que no sucede con la de la Iglesia ortodoxa que es tan sólo legal". De esta manera, prosigue Salinas, "una eventual cancelación de la personalidad jurídica de la Iglesia católica, además de ley de la República, exigiría una reforma constitucional". No compartimos esta radical conclusión, a la luz de los argumentos ya dados al tratar los precedentes constitucionales, quedándonos con la opinión de Luis Eugenio Silva, muy clarificadora al respecto ${ }^{40}$.

En lo que respecta al derecho matrimonial, la aprobación de la ley № 19.947 trajo consigo no sólo la introducción del divorcio en el ordenamiento civil chileno, sino además el reconocimiento -al menos simbólico- del matrimonio celebrado en forma religiosa, en tanto dicho matrimonio sea realizado por una entidad religiosa que goce de personalidad jurídica de derecho público. En esta última situación se encuentran tanto la Iglesia católica como la Iglesia ortodoxa ${ }^{41}$.

El punto remite al debate sobre la validez civil del matrimonio canónico y, especialmente, a la correspondencia válida de la propiedad de la indisolubilidad entre ambos ordenamientos jurídicos. Sobre el primer aspecto, la cuestión queda dirimida sobre la base de la determinación del sistema matrimonial vi-

\footnotetext{
${ }^{38}$ Precht Pizarro, Jorge, "La Iglesia católica: su autopercepción y la ley № 19.638", en Del Picó, Derecho, cit. nota n. 1, p. 185.

${ }^{39}$ SALINAS, "Las fuentes", cit. nota n. 1, p. 197. Un interesante análisis sobre la naturaleza jurídica de la Iglesia Católica, en una apreciación que une diferentes perspectivas sobre el concepto de iglesia, es tratado en PRECHT, Derecho, cit. nota n. 24, pp. 227-243.

${ }^{40}$ Salinas, Lecciones, cit. nota n. 1, p. 280, en concordancia con lo expuesto por Silva Cuevas, Luis Eugenio, "Dimensión histórica...", en Humanitas, cit. nota n. 16, p. 7.

${ }^{41}$ Cfr. Del Picó Rubio, Jorge, Derecho matrimonial chileno, Abeledo Perrot, Santiago de Chile, 2010, pp. 309-370.
} 
gente, el que se incluye entre aquellos que contemplan un régimen civil que determina los requisitos sustantivos referidos a la capacidad de los contrayentes y los efectos personales y patrimoniales del matrimonio válidamente celebrado, abriendo la celebración del mismo a las formas exigidas por las confesiones religiosas que cumplen los requisitos legalmente establecidos. Respecto del segundo aspecto, el respeto de la validez del matrimonio celebrado en sede eclesiástica, determina que, en el supuesto de un requerimiento de divorcio por parte de uno de los cónyuges ligados en matrimonio católico, los tribunales civiles deberán proceder a dictar el cese de los efectos civiles del matrimonio, sin pronunciarse respecto de la subsistencia del vínculo religioso ${ }^{42}$.

En lo que respecta a la cuestión jurisdiccional y una eventual contienda de competencias, según sea la base a partir de la cual se aborden los problemas emergentes, la existencia armónica entre el derecho estatal y los derechos particulares, en este caso el de la Iglesia católica, será sometida a previsibles presiones, derivada de la alta connotación pública que han adquirido los casos de abusos contra la integridad física y síquica de menores de edad cometidos por clérigos, los que han impactado severamente en el conjunto de la sociedad y, en particular, en la comunidad católica. Además de los casos observados en los últimos veinte años, las causas abiertas a partir de las denuncias interpuestas en contra del sacerdote Fernando Karadima y de la religiosa superiora de la Congregación de las Ursulinas, son particularmente relevantes, no sólo por la gravedad de los hechos denunciados sino, especialmente, en la perspectiva del Derecho eclesiástico, por las múltiples intersecciones que se suscitan entre el ordenamiento estatal y el eclesiástico, como ocurre con la facultad de registro de lugares religiosos, el derecho a solicitar información sobre los procesos canónicos en curso, la obligación de

\footnotetext{
${ }^{42}$ Un completo y actualizado análisis sobre las cuestiones involucradas, es realizado por Anastasía Assimakópulos en su tesis doctoral, recientemente defendida, particularmente en la segunda parte de la misma, en la cual aborda con propiedad el matrimonio canónico y su recepción en la Ley de Matrimonio Civil en el contexto del reconocimiento de los matrimonios religiosos (Cfr. Assimakópulos FigueroA, Anastasía, El matrimonio canónico con efectos civiles en el Derecho chileno: sobre la naturaleza y consecuencias de su recepción en virtud de la ley de matrimonio civil, Tesis para optar al grado de Doctor en Derecho por la Universidad de los Andes, Santiago de Chile, 2011, pp. 123 y ss.). Para un análisis de las implicancias derivadas de las iniciativas legislativas posteriores a la entrada en vigor de la ley $N^{\circ} 19.947$, en especial el eventual reconocimiento de las uniones de hecho y la formalización civil de las uniones entre personas del mismo sexo, vide Dé PICó Rubıo, "La unión conyugal basada en la diferencia de sexo en la Ley $N^{\circ} 19.947$ y los proyectos de reconocimiento jurídico de las uniones homosexuales en Chile", en Domínguez Ácuila, Ramón (Coord.), Estudios de Derecho civil V, Abeledo Perrot, Santiago de Chile 2010, pp. 285-296. Otra perspectiva en SAlinas AranedA, Carlos, "El Derecho eclesiástico del Estado de Chile: novedades recientes", Revista de Derecho de la Universidad Católica de la Santísima Concepción, 22, 2010, pp. 98-100, e ídem, "El reconocimiento del matrimonio religioso en el Derecho positivo del Estado de Chile: un viejo tema aún pendiente", Revista de Derecho Universidad Austral de Chile, XXIII, 2010, pp. 59-78.
} 
denuncia de los delitos que pesa sobre los ministros de culto y las ostensibles diferencias de apreciación de la efectividad de los procesos en sede judicial y en sede canónica, diferenciada además en este último caso entre la iniciativa local y aquella originada en la Santa Sede. Sobre la materia, aún en desarrollo, me remito a lo expresado por Salinas, en una reciente evaluación sobre los avances del Derecho eclesiástico en Chile ${ }^{43}$.

Finalmente, en lo que atañe a la personalidad jurídica de derecho público preexistente de la Iglesia Católica Ortodoxa de Chile (Iglesia ortodoxa), tributaria del Patriarcado de Antioquía, cabe decir que esta entidad religiosa, con presencia histórica en Chile, obtuvo el reconocimiento como persona jurídica de derecho público por medio de la ley $N^{\circ} 17.725$, publicada en el Diario Oficial el 25 de septiembre de 1972, patrocinada y redactada por el senador democratacristiano José Foncea Aedo, durante el Gobierno del Presidente Allende. La Iglesia Católica, como lo recuerda Precht, no se opuso a su reconocimiento legal ${ }^{44}$.

Sin perjuicio de la similitud de la naturaleza jurídica de la personalidad de derecho público que ostentan tanto la Iglesia Católica como la Iglesia Ortodoxa, Salinas distingue dos diferencias que atienden al origen y carácter de la formalización jurídica respectiva. La primera, cuestionable como ya he anticipado, considera que la personalidad jurídica de la Iglesia Católica tiene fundamento constitucional, en tanto que la de la Iglesia ortodoxa sería meramente legal. La segunda, que la ley N $N^{0} 17.725$ "concedió" personalidad jurídica a esta iglesia y, por tanto, sería impropio hablar de "reconocimiento". Si bien la distinción es correcta, se explica, a nuestro juicio, por la concepción jurídico administrativa predominante en la época, muy lejana aún a las modernas y complejas implicancias de la noción de reconocimiento en las relaciones entre religión y Estado. Un último aspecto destacado, es que la ley dispuso que la persona jurídica de derecho público Iglesia ortodoxa, debía regirse por sus estatutos y por las normas canónicas y aplicables a dicha institución religiosa, constituyendo un caso de remisión del derecho chileno al derecho particular de la Iglesia ortodoxa ${ }^{45}$.

Durante la tramitación del proyecto de ley en el Congreso Nacional, las autoridades de esta entidad religiosa habían manifestado en dos oportunidades, en cartas dirigidas a los Presidentes del Senado durante dicho período, su oposición a la posibilidad que el proyecto en trámite pudiera alterar el régimen jurídico que el legislador ya le había reconocido en Chile. Dicha aspiración, en defini-

\footnotetext{
43 Salinas, "El Derecho", cit. nota n. 41, pp. 102-106.

${ }^{44}$ Precht Pizarro, Jorge, "Un caso de mutación legislativa: la ley de iglesias", cit. nota n. 16, p. 9.

${ }^{45}$ Cfr. Salinas, "Confesiones", cit. nota n. 34, p. 139.
} 
tiva, fue cautelada en el nuevo cuerpo legal, con su consagración explícita en el artículo 20 de la ley, y en virtud de la cual la Iglesia Ortodoxa del Patriarcado de Antioquía conserva la calidad de persona jurídica de derecho público ${ }^{46}$.

\section{Nota SObRe EL REGISTRO PÚBLICO DE LAS ENTIDADES RELIGIOSAS ACOGIDAS AL RÉGIMEN ESPECIAL DE CONSTITUCIÓN JURÍDICA}

Una cuestión accesoria, pero no menos relevante si se atiende a sus efectos, se ha abierto con motivo de la constitución de un registro histórico de entidades amparadas en el art. 20 de la LC, vale decir, que incluye la información disponible sobre la Iglesia Católica y la Iglesia Ortodoxa.

Al respecto, cabe consignar que la decisión administrativa del Ministerio de Justicia, concordada con las autoridades eclesiásticas de la época, tiene plena justificación en la necesidad pública de disponer de los antecedentes básicos que configuran la organización eclesiástica, en su dimensión civil, de dichas entidades, con una finalidad eminentemente informativa, tanto para los funcionarios que deben cumplimentar gestiones que digan relación con estas entidades, así como también de todas aquellas personas que requieran información fidedigna que, por lo demás, tiene carácter público y no reservado.

En contrario, Precht manifiesta su disconformidad con el sistema, expresando su preferencia por un sistema pactado que no se concretó. Funda la duda respecto del carácter y sentido de la creación del registro histórico, toda vez que para este autor, debe quedar claro el carácter constitutivo simple de este registro, en el sentido de brindar publicidad a estas entidades y así contribuir a la seguridad del tráfico jurídico. Sin embargo, la prevención debe darse por satisfecha ya que, como se ha dicho, éste y no otro es el propósito del registro histórico ${ }^{47}$.

En los hechos, y más allá de esta crítica, el denominado registro o expediente histórico ha sido de gran utilidad práctica, brindando seguridad jurídica a las entidades históricas y a quienes se relacionan con ellas, al disponer de un respaldo material público sobre la información concerniente a las entidades religiosas cuyo ordenamiento reconoce el art. 20 de la LC. Estos antecedentes, primariamente validados por el Estado, brindan apoyo a la reserva del uso privativo de aquellas denominaciones, ritos y otros elementos que configuran no solo el patrimonio jurídico de estas instituciones sino además concurren a formar

\footnotetext{
${ }^{46}$ Vide Elgueta Barrientos, Sergio, "Libertad religiosa y de culto", en Del Picó, Ley, cit. nota n. 1, p. 99.

47 Vide Precht Pizarro, Jorge, "La Iglesia católica y su auto percepción...", cit. nota n. 16, p. 185. Se refiere al registro, al cual denomina "expediente", la asesora de la Conferencia Episcopal Ana María Celis, en Celis Brunet, Ana María, "Iglesias y Estado en la República de Chile", en Navarro Floria, Juan (Coord.), Estado, derecho y religión en América Latina, Marcial Pons, Madrid 2009, pp. 133-137.
} 
parte de su propia identidad en la sociedad en la que desarrollan su acción propia, como ocurre con frases y términos tales como el propio nombre de la Iglesia Católica chilena, salvaguardado efectivamente este derecho frente a las pretensiones de terceros, actuando de buena o mala fe, mediante la certificación de los datos contenidos en el registro.

\section{SÍNTESIS CONCLUSIVA}

1. El legislador, por medio de las normas de la LC, estableció un régimen general y un régimen especial de reconocimiento por parte del Estado de la personalidad jurídica de las entidades religiosas en Chile. En ambos casos, se contempla el reconocimiento de la personalidad jurídica de derecho público, no existiendo discriminación alguna entre las entidades acogidas a uno u otro sistema.

2. El sistema general de reconocimiento de la personalidad jurídica, contemplado en el artículo 10 de la LC, además de facilitar el proceso constitutivo, ha permitido mutar desde la calidad de persona jurídica de derecho privado a la calidad de persona jurídica de derecho público a diferentes entidades religiosas minoritarias, principalmente evangélicas, las que han visto reflejadas en sus normas la voluntad igualitaria expresada por el legislador.

3. El sistema especial de constitución jurídica, contemplado en la norma de consenso incluida en el artículo 20 de la ley, permitió destrabar la aprobación de la LC, resguardando los derechos adquiridos de las iglesias históricas, entre las cuales se encuentra la religión mayoritaria de la población.

4. El régimen especial contempla, básicamente, el reconocimiento de la personalidad jurídica y el derecho a mantener inalterado el régimen jurídico propio -que se traduce principalmente en el ordenamiento interno de la entidad-con el cual contaban al momento de la publicación de la LC.

5. Se agrega a los efectos ya indicados, una prevención legal ante la ocurrencia de posibles tratos desiguales respecto de las entidades que gozan de una personalidad jurídica diferente, cuya eventual utilidad revisaremos más adelante, al igual que el carácter obligatorio o facultativo que tiene la posible mutación de la naturaleza jurídica de la personalidad ya reconocida.

6. Junto con facilitar la aprobación de la LC en su oportunidad, además resolvió la cuestión histórica sobre el origen y la naturaleza de la personalidad jurídica de la Iglesia católica en Chile.

\section{BibLiOGRAFíA}

Alessandri Rodríguez, Arturo; Somarriva Undurraga, Manuel, Curso de Derecho Civil, $2^{a}$ Edición redactada y puesta al día por Vodanovic, Antonio, Nascimento, Santiago de Chile, Nascimento, 1945. 
Assimakópulos Figueroa, Anastasía, El matrimonio canónico con efectos civiles en el Derecho chileno: sobre la naturaleza y consecuencias de su recepción en virtud de la ley de matrimonio civil, Tesis para optar al grado de Doctor en Derecho por la Universidad de los Andes, Santiago de Chile, 2011.

Cenalmor, Daniel; Miras, Jorge, El Derecho de la Iglesia, Conferencia Episcopal Latinoamericana, Ediciones Universitarias de Navarra, Quito, 2004.

Del Picó Rubio, Jorge (Coord.), Ley de cultos y documentos complementarios, Konrad Adenauer Stiftung, Instituto Chileno de Estudios Humanísticos, Santiago de Chile, 2000.

(Coord.), Derecho de la libertad de creencias, Abeledo Perrot, Santiago de Chile, 2010.

Chile, 2010.

Derecho matrimonial chileno, Abeledo Perrot, Santiago de

Domínguez Águila, Ramón (Coord.), Estudios de Derecho Civil V, Abeledo Perrot, Santiago de Chile, 2010.

instituto Martín De Azpilcueta, Código de Derecho canónico, quinta edición revisada y actualizada, Ediciones Universidad de Navarra, Pamplona, 1992.

Lagos Schuffeneger, Humberto, Chile y el mito del Estado laico, Icthus, Santiago de Chile 2005.

Lyon Puelma, Alberto, Personas jurídicas, Ediciones Universidad Católica de Chile, $4^{\text {a }}$. edición ampliada, Santiago de Chile, 2006.

Morales Galindo, Ricardo, Posición jurídica de las asociaciones de fieles en el derecho chileno, Orden de la Merced, Santiago de Chile 2000.

Navarro Floria, Juan, Acuerdos y concordatos entre la Santa Sede y los países americanos, Editorial de la Universidad Católica Argentina, Buenos Aires 2011.

(Coord.), Estado, derecho y religión en América Latina, Marcial Pons, Madrid, 2009.

Pizarro Wilson, Carlos (Coord.), Estudios de Derecho Civil IV, LegalPublishing, Santiago de Chile, 2009.

Precht Pizarro, Jorge, 15 Estudios sobre Libertad Religiosa en Chile, Ediciones Universidad Católica de Chile, Santiago de Chile, 2006.

Derecho eclesiástico del Estado de Chile, Ediciones Universidad Católica de Chile, Santiago de Chile, 2000.

Salinas Araneda, Carlos, Lecciones de Derecho eclesiástico del Estado de Chile, Ediciones Universitarias de Valparaíso, Valparaíso, 2004.

Publicaciones periódicas

Anuario de Derecho Eclesiástico del Estado, XXVI, 2010.

Anuario de Derecho Eclesiástico del Estado, XVIII, 2002. 
Revista Humanitas 9, Separata VII, 1998.

Revista de Derecho Universidad Austral de Chile, XXIII, 2010.

Revista de Derecho de la Universidad Católica de la Santísima Concepción, 22, 2010.

Revista de Derecho de la Universidad Católica de Valparaíso, XXI, 2000.

Diario El Mercurio de Santiago, jueves 15 de mayo de 2003, cuerpo c, p. 9.

\section{Documentos}

Senado de la República, Diario de Sesiones del Senado, Legislatura № 340 ordinaria, sesión 10, de 6 de julio de 1999.

Conferencia Episcopal de Chile, Declaración Pública de la Conferencia Episcopal de Chile, 25 de mayo de 1999.

Conferencia Episcopal de Chile, Comunicado de prensa sobre la actitud de de la Iglesia Católica en Chile ante los abusos contra menores cometidos por un clérigo o un religioso, 25 de abril de 2003. 